\title{
Comparative Anatomical Study of the Pelvic Limb Skeleton in the Chinchilla (C. Lanigera) and in the Domestic Rabbit (O. Cuniculus)
}

\author{
Adriana CHENDE ${ }^{1}$, Irina IRIMESCU ${ }^{1}$, Florin GHIURCO $^{1}$ and Aurel DAMIAN ${ }^{1}$ \\ ${ }^{1}$ Faculty of Veterinary Medicine, University of Agricultural Sciences and Veterinary Medicine of Cluj- \\ Napoca, Calea Mănăştur, nr. 3-5, 400372, Cluj-Napoca, Romania; \\ *Corresponding author e-mail: catedra1mv@yahoo.com
}

Bulletin UASVM Veterinary Medicine 71(2) / 2014,

Print ISSN 1843-5270; Electronic ISSN 1843-5378

DOI:10.15835/buasvmcn-vm: 10499

\begin{abstract}
The current growing trend of Chinchilla husbandry for pets creates a demand for generating a detailed anatomic data base of this species. Taking into account the existing initiatives of osteology and osteometry research our study aimed to compare the pelvic limb skeleton of the Chinchilla to that of the Domestic Rabbit, in order to highlight the differences.10 pelvic limb skeletons of adult Chinchillas were compared to 10 Domestic Rabbit pelvic limbs skeletons belonging to our ossuary. Examination underlined several particularities: the wing of the chinchilla's ilium is narrower than that of the rabbit's, the gluteal crest is very prominent and continues on the lateral side of the neck of ilium, ending in a tubercle, caudally to the acetabulum. The femur misses the third trochanter present in rabbits. The tibia and the fibula of the Chinchilla are not fused in the distal two thirds of the diaphysis. The Chinchilla's fibula is a complete bone, having the same length as the tibia, ending by a rounded lateral malleolus. The similitude to the Rabbit is that the two bones present a visible but narrow proximal interosseous space. Both species present a similar autopodium, although the fifth toe is shorter in Chinchillas, composed of two phalanges. In conclusion, the coxal, the femur, the tibia and fibula of the Chinchilla present several distinct elements when compared to Domestic Rabbits, which provide details useful for clinical examination and further articular and muscular research in this species.
\end{abstract}

Keywords: pelvic limb skeleton, Chinchilla lanigera, Oryctolagus cuniculus

Introduction. Chinchillas (C. lanigera) are a rodent species from the Andes have become highly appreciated furbutalso growingin popularity as house pets. Anatomic data on this species is currently being gathered (Stan et al., 2014) and, although existing osseous descriptions and imaging are available (ÇevikDemirkan et al., 2007; Silverman and Tell, 2005), details regarding the Chinchilla's skeleton are limited. The Domestic Rabbit (O. cuniculus), is provided with sufficient background anatomic descriptions (Barone, 1986; Damian et al., 2001) to serve as reference for the taxonomically related Chinchillas.

Aims and objectives. Our study aimed to deliver a detailed description of the Chinchilla's thoracic limb skeleton features, using the Domestic Rabbit as reference, in order to advance the anatomical knowledge on this species and to offer data for clinicians.
Materials and methods. 10 pelvic limbs of commercial slaughtered adult Chinchillas of both sexes were processed by maceration to obtain the bones. The examination was done by comparison to 10 pelvic limb skeletons of adult Domestic Rabbit from our ossuary.

Results and Discussion. The coxal bone of the Chinchilla has a straight almost horizontal axis, with a smooth ischium and pubis, delimiting a large ovoid obturator foramen (Fig. 1a). The ilium has an elongated wing, narrower than that of the Rabbit's. Its lateral surface presents a very prominent gluteal crest that continues on the lateral side of the neck of the ilium, ending in a tubercle, caudally to the acetabulum. This crest completely splits the gluteal fossa into two swallow elongated surfaces: a dorso-lateral fossa and a ventro-lateral one. The proximal epiphysis of the femur lacks the 


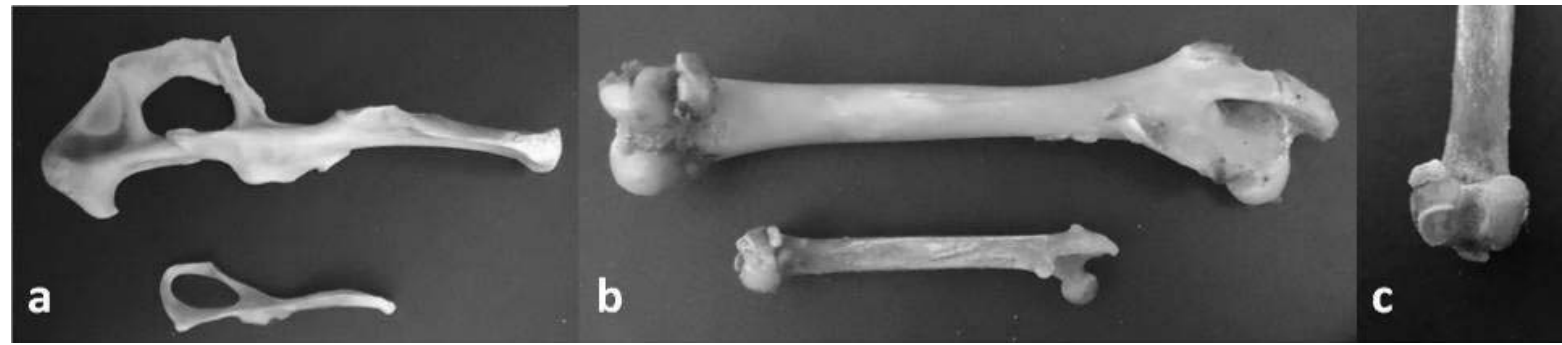

Fig. 1. (a) Coxal bone in the Rabbit (up) and in the Chinchilla (down); (b) caudal view of the femur in the Rabbit (up) and in the Chinchilla (down); (c) detailed view of the distal condyles of the femur in the Chinchilla, with one visible femoral sesamoid bone.

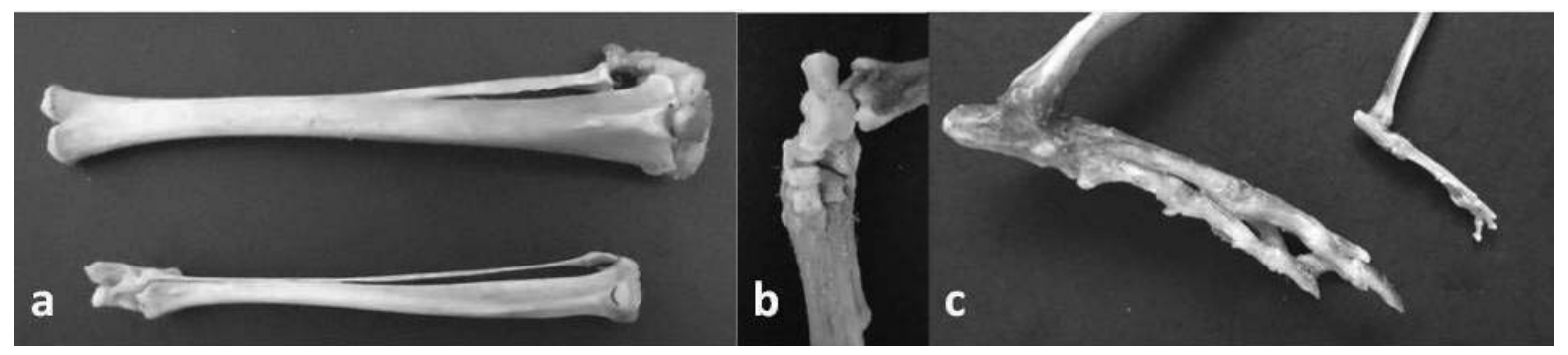

Fig. 2. (a) cranial view of the tibia and fibula in the Rabbit (up) and in the Chinchilla (down); (b) cranio-dorsal view of the tarsal bones in the Chinchilla; (c) lateral view of the autopodium in the Rabbit (left) and in the Chinchilla (right).

third trochanter present in Rabbits. However, the positioning of the greater and lesser trochanters lead to a vertical intertrochanteric crest. The articular head is also different in Chinchillas, being well detached from the epiphysis by a thin neck. The femoral diaphysis and distal epiphysis are similar in the two species, including the presence of two femoral sesamoid bones (Fig. 1b and 1c). The tibia and the fibula of the Chinchilla also present major differences from those of the Rabbit: they are not fused in the distal two thirds of the diaphysis (Fig. 2a). The Chinchilla's fibula is a complete bone, having the same length as the tibia, ending by a rounded lateral malleolus. The similitude to the rabbit is that the two bones present a visible but narrow proximal interfossa and have a coalescence rapport distally. The autopodium of both species is of plantigrade type, of similar tarsal (Fig. 2b) and metatarsal structure (Fig. 2c), featuring metatarsal and distal sesmaoid bones. The Chinchilla presents a shorter fifth toe, composed of only two phalanges. Our findings are in concordance with descriptive and imaging data from literature (Silverman and Tell, 2005; ÇevikDemirkan et al., 2007).
Conclusion. The pelvic limb skeletons of the Chinchilla presents several differences from that of the Domestic Rabbit (in the coxal bone, the femur, the tibia and fibula, and the fifth toe) suggesting articular and muscular insertion particularities. These findings are relevant for correct imaging diagnosis and further studies of the locomotion in this species.

\section{References}

1. Barone R (1986). Anatomie comparée des mammifères domestiques - Tome 1 : Ostéologie - 3ème ed., Ed. Vigot, Paris.

2. Cevik-Demirkan A, Özdemir V, Türkmenoğlu İ, Demirkan İ. (2007). Anatomy of the Hind Limb Skeleton of the Chinchilla (Chinchilla lanigera), Acta Vet. Brno 2007, 76: 501-507; DOI:10.2754/avb200776040501.

3. Damian R, Popovici N, Chirilean Ioana (2001). Anatomie comparată sistemul de susţinere şi mişcare, Ed. AcademicPres, Cluj-Napoca.

4. Silverman S, Tell LA (2005). Rodents, Rabbits and Ferrets: An Atlas of Normal Anatomy and Positioning, Ed. Elsevier Saunders, St. Louis, Missouri.

5. Stan F, Damian A, Gudea A, Dezdrobitu C, Bob Delia, Martonos C, Bochiş Ileana, Pogana B (2014). Comparative Anatomical Study of the Large Intestine in Rabbit and Chinchilla, Bulletin UASVM Veterinary Medicine 71 (1) / 2014, 208-212. 